\title{
Establishment Of Absolute Gravity Stations Referenced To International Gravity Station Network Of 1971 Datum In County Levels In Kenya
}

\author{
Korir H. K. ${ }^{1 *}$, Githiri J. G. ${ }^{1}$ and K'orowe M. O. ${ }^{1}$ \\ ${ }^{I}$ Department of Physics, Jomo Kenyatta University of Agriculture and Technology, P. O. BOX 62000 Nairobi, \\ Kenya
}

\begin{abstract}
Gravimeters measure relative readings and to obtain absolute gravity values, they have to be referenced to a station whose gravity is accurately known. International Gravity Stations Network (IGSN) consists of stations distributed all over the world whose absolute gravity has been measured accurately. In Kenya there are three IGSN 71 stations located in Nairobi, Kisumu and Mombasa. To carry out gravity survey at any location in Kenya, at least one of the three reference IGSN station has to be used as a reference station. The stations are sparsely spaced and there is need to establish more stations closer for any researcher conducting local surveys. A Worden Sodin gravimeter was used to measure relative gravity in a specific location at every county survey headquarters in Kenya. This reading was referenced to the IGSN 71datum to obtain its absolute gravity reading. Calibration constant of $0.75423 \mathrm{mgal} / \mathrm{div}$ was used to convert gravimeter readings to gravity units. A globally distributed network of absolute gravity stations is essential in; geodynamic studies, global climate change monitoring, providing reference values for the other organizations operating gravity instruments. This also will support international studies of secular variations of gravity.
\end{abstract}

Keywords: Datum, Honkasalo term, Gravimeter, Network

\section{Introduction}

A datum is a reference from which measurements are made and are typically used for relative quantities. The need for gravity datum is connected to the instruments used to measure gravitational acceleration and the establishment of reference stations.

Historically, the instruments used to make absolute gravity measurements had poor accuracies. Thus, most instruments used to measure gravity were relative instruments. Relative instruments determine the gravity difference between station with known gravity value and new station. Relative instruments may be used to measure gravity difference of a site relative to a national base station. Therefore it is possible to establish other reference base stations. Both simple pendulum and spring-based gravimeters could make relative measurements reliably, quickly, and accurately. Before the 1960s, the only accurate way to make an absolute measurement was with a reversible pendulum done in laboratory conditions [1].

In the late $19^{\text {th }}$ century, the Vienna Gravity System was established by F.R.Helmert based on pendulum measurements in Vienna, Austria [1]. This system had an estimated relative accuracy of \pm 10 mGals. By 1909, this system was replaced by the Potsdam Gravity System, which had a relative accuracy of \pm 3 mGals and corrected the Vienna System by 16 mGals. However in the 1960s, it was realized that the Potsdam datum was off by about -14 mGals. However, until a better system could be devised, world experts agreed that it was better to leave all measurements on a single datum. In the late 1950s and 1960s, concerted efforts were made to make new worldwide pendulum and spring based gravimeter ties and to include the new ballistic absolute gravimeter measurements in the adjustment [2]. These data were combined and solved simultaneously and published as the International Gravity Standardizartion Net 1971 (IGSN-71). About 1,900 worldwide sites, including about 450 U.S. sites, were in this network. Each site had an estimated standard error of less than $\pm 50 \mu$ Gals, with a correction of \pm 14.0 mGals at the Potsdam site [3]. The IGSN-71 remains the official gravity datum worldwide today.

Since the 1960s, numerous ballistic, absolute gravimeters have been made. Today, these gravimeters make routine measurements with accuracies of under $\pm 10 \mu \mathrm{Gals}$ [4]. Modern absolute gravimeter measurements loosely confirm the IGSN-71 values, within its error limits. The absolute gravimeter measurements are technically their own datum, since they measure gravity directly without relative ties to any other stations. Internal design elements and the ways they are combined to make a gravimeter cannot guarantee that the published number is a 'true' gravity value any more than old pendulum gravimeter could. The best researchers can do is to compare gravimeters to each other to be sure they are all measuring similarly and thus have a semblance of being a datum. 
In Kenya, gravity measurements started way back in 1955. A catalogue of gravity measurements [5] contains compilation of these data all the way from 1955 to 1975. This compilation is one of the end products of a research programme which began at Leicester University in 1965. It supersedes previous catalogues by Searle and Darracot [6] and Khan, Mansfield and Swain [7]. The datum used in reducing the gravity observations is defined by the IGSN-71 [8] together with the 1967 gravity formula as recommended by the IUGG.[3].

In December 1979, The New Geodetic Reference System 1980 was adopted at the XVII General Assembly of IUGG in Canberra. The International Union of Geodesy and Geophysics (IUGG) recognizing that the Geodetic Reference System 1967, adopted at the XIV General Assembly of IUGG in Lucerne 1967, no longer represent the size, shape and gravity field of the Earth to an accuracy adequate for many geodetic, geophysical, astronomical and hydrographic applications and considering that more appropriate values are now available, recommends that the Geodetic Reference System 1967 be replaced by a new Geodetic Reference System 1980 [9].

It is evident that the gravity data contained in the Catalogue of gravity measurements [5] are not updated to meet the current accuracy standards required for application in the field of geosciences, yet it is the major document known to contain homogenous gravity data of Kenya which have been referenced to IGSN-71 station. IGSN-71 values include a correction of the Honkasalo term [12] which removes the average part of the tidal force. This correction term has been deemed inappropriate [13] because of resulting errors in calculation of the geoid from gravity values corrected with the Honkasalo term. This calls for the need to update the data to meet standards recommended by IUGG and set up accessible absolute gravity stations distributed evenly in the country. With availability of Global positioning devices (GPS) with accuracy of $\pm 3 \mathrm{~cm}$ thus, challenges encountered by early researchers in height and position measurement will be solved. Also by application of the new Geodetic Reference formulae of 1980 to the data, more accurate theoretical values of gravity at sea level will be achieved.

\subsection{Study Area}

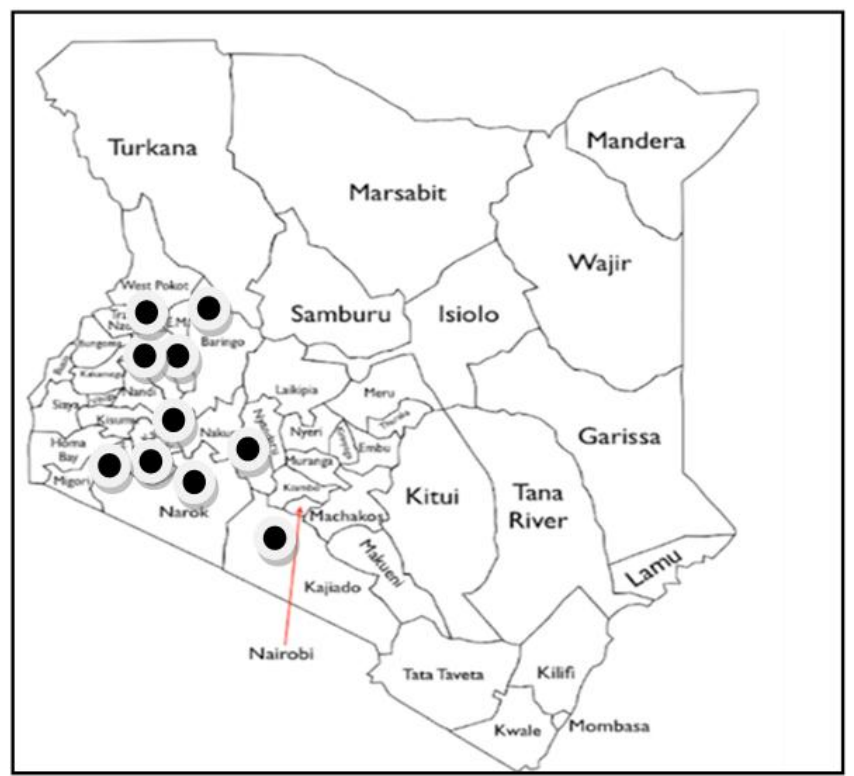

Figure 1: Map of Kenya showing locations where absolute gravity stations have been established

New absolute gravity stations were set up in 10 counties within the rift-valley region of Kenya. The counties are; Kajiado, Narok, Bomet, Kisii, Kericho, Nakuru, Baringo, El geiyo Marakwet, Tranz Nzoia, and Uasin Gishu as shown by the doted points in figure 1 above.

\section{Materials And Methods}

Worden Sodin gravimeter model 403 was used to measure the gravity difference between the new station and the reference stations. Global positioning system (GPS) was used to measure the co-ordinates and height above sea level of the new station. It was also used to locate the physical locations of the reference points as indicated in the catalogue of gravity measurements in Kenya by Swain and Khan [5].

The gravimeter was monitored for a period of 1 week, before commencement of the field work, to ascertain its consistency. A location was chosen near university football field, where gravimeter readings were recorded three times a day; morning, after noon, and evenings, for a period of seven days. It was found out that the gravimeter was giving nearly consistent readings with a small deviation of approximately 0.2 dial units as shown in the chart below. 


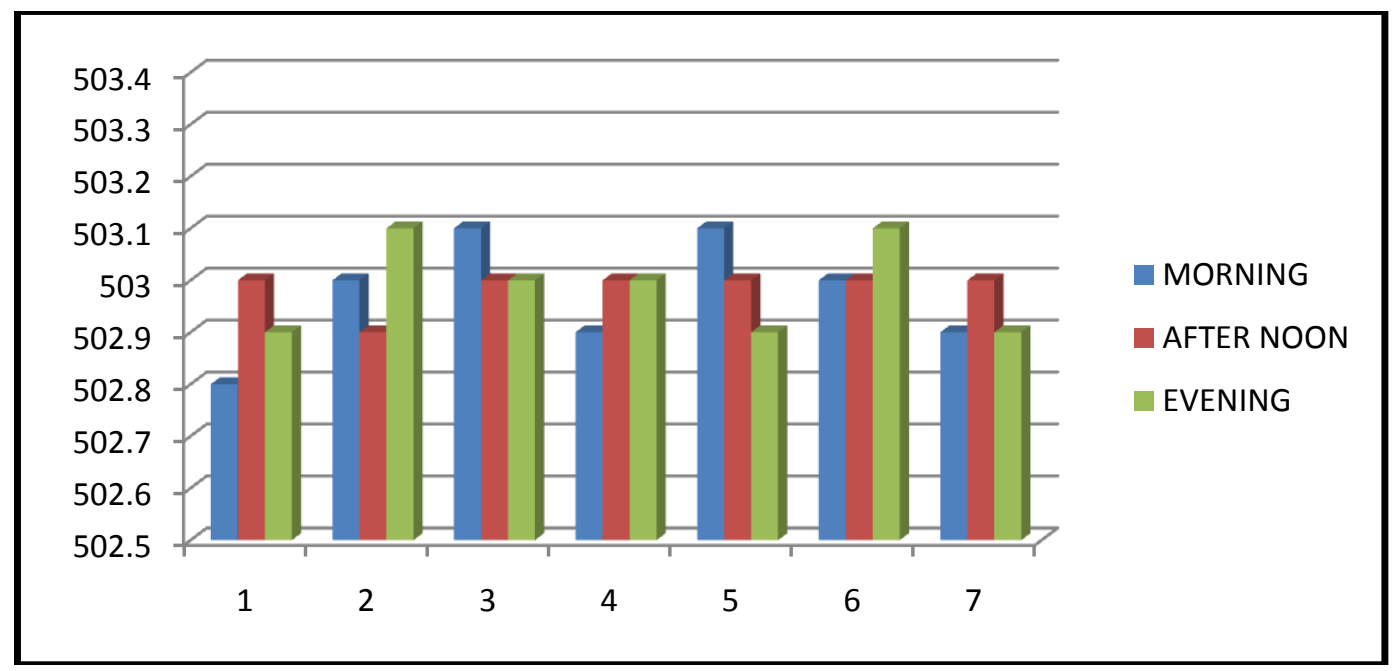

Figure 1: Chart showing variation of gravimeter readings at one location.

During field work, regular checks were performed to the gravimeter to insure that the levels and sensitivity settings were properly adjusted. These checks were performed daily before commencing data collection. The first check was to insure that the cross level of the gravimeter was exactly in the horizontal position when its bubble was in the mid range. This test was quite important since if the gravimeter was tipped in one side or the other it won't measure the full force of gravity. The second test was to check sensitivity of the reading line. The reading line could be highly sensitive or low sensitive which could cause uncertainties in adjusting the cross hair during data collection. These tests were a must to insure that the gravimeter was adjusted and will measure gravity acceleration precisely.

A suitable location for establishing the new station was based on the following conditions as stipulated by Boedecker [10]; firstly, the location was supposed to be stable in terms of structural, hydrological and geological conditions. Secondly, the location was to be a way from highways, railroads, electrical power supplies and be accessible $24 \mathrm{hrs}$ a day, 7 days a week. Lastly, the location was supposed to be suitable for setting up gravimeters, GPS receivers, and precise leveling rods.

The basic survey procedure in gravity survey is the loop. This procedure is required to computationally remove the systematic drift error of the instrument and to provide redundant observations at stations for quality assurance purposes. A loop consists of a set of gravity stations for which gravity differences are observed by the same observer and the same gravimeter [11]. For this case a profile method loop was adopted as a survey scheme to collect data. With four stations whose absolute gravity values are known for example stations; 1, 3, 4, 5 and a station whose gravity value is to be determined for example station 2, the procedure for data collection was as follows; 1-2-3-4-5-5-4-3-2-1. The procedure is well shown in the figure below. This method is efficient and cheap. It is also a method with single, double or multiple station occupation at continuous station occupation in the profile.

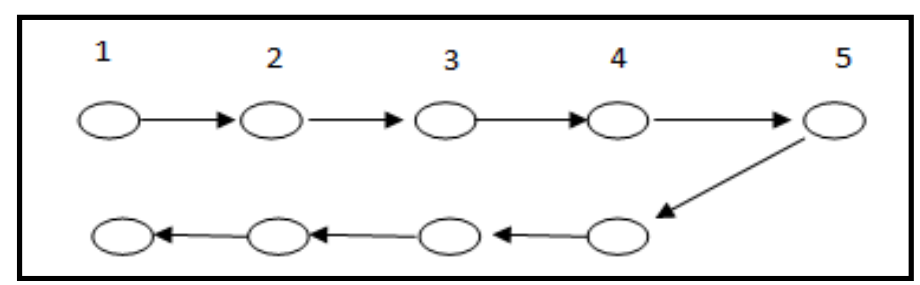

Figure 2: The Profile Method

At each site three consecutive readings of the gravimeter were recorded in less than 5 minutes. In the data processing stage, the average of these readings was taken as a unique observation of that station. The field work sheet showing data collected for setting up a new station (Kajiado County) is as shown below;

Table 1: Gravimeter readings at new station and reference stations in Kajiado County, Kenya

\begin{tabular}{|l|l|l|l|l|}
\hline KAJIADO COUNTY, KENYA & Absolute Gravity & $1^{\text {st }}$ Reading & $2^{\text {nd }}$ Reading & $3^{\text {rd }}$ Reading \\
\hline New Station & & 501 & 501.5 & 499 \\
\hline $1^{\text {st }}$ Reference Station & 977562.4 & 496.0 & 496.5 & 496.3 \\
\hline $2^{\text {nd }}$ Reference Station & 977585.3 & 524.8 & 523.1 & 524.3 \\
\hline $3^{\text {rd }}$ Reference Station & 977587.5 & 533 & 531.4 & 532.9 \\
\hline
\end{tabular}




\subsection{Reduction of the Observed values}

\section{Data Analysis}

\subsubsection{Drift Correction}

The main reason for collecting data based on the profile method was to investigate gravimeters drift. This was achieved by observing graphically the dial readings at each station for the first leg of the loop and the return leg. This was possible by plotting the "dial readings" versus "station position". Example for Kajiado County is shown graphically below. The same procedure was applied to the other counties and it was observed that the gravimeter gave consistent dial readings in each station. Small 'jumps' was observed in Bomet, Narok, and Kajiado counties, this was attributed to small errors in leveling internal spirit level in the gravimeter. In other counties, difference between the first line and the second line could not be observed due to nearly perfect consistency in dial readings.

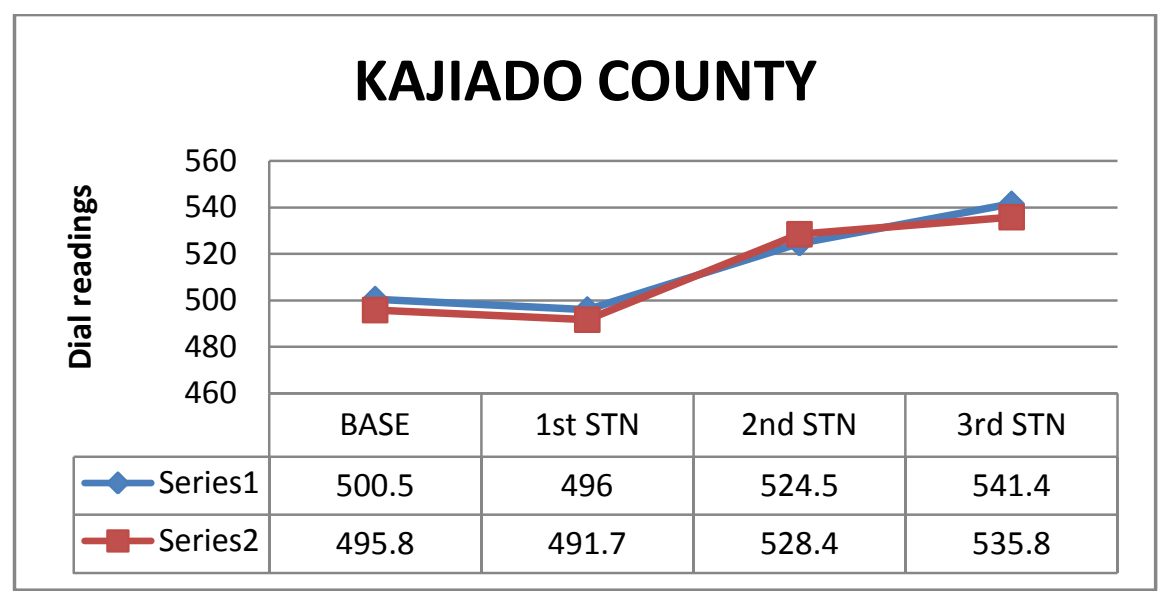

Figure 3: Curve showing variation of dial readings at each station

It was evident that the gravimeter did not drift much, so in order to obtain the dial reading representing a station, a weighted average of the two dial readings was calculated.

\subsubsection{Tidal Correction}

Variations in the configuration of the Earth, Moon, and Sun cause the lunar-solar attraction at a particular point on the Earth to vary as much as 280 microgals ( $\mu$ gal). This attraction has significant effect on gravity observation on the earth's surface. Since data for a particular day were taken within a span of 2 hours and locations of reference points were approximately within a radius of $3 \mathrm{~km}$, it is assumed that the tidal effect on gravimeter readings were uniform on that particular day. Thus this effect is eliminated during calculations.

\subsubsection{Earth's Magnetization}

A fixed orientation with respect to the local magnetic north was observed throughout the measuring campaign in order to minimize possible beam magnetization.

\subsection{Updating Gravity values of the Reference Stations}

3.2.1. Conversion from 1967 Geodetic reference system to 1980 geodetic reference system.

The gravity values in the catalogue of Khan and Swain [5] were computed based on the 1967 Geodetic Gravity formula yet in 1979 a new gravity formula was adopted by the International Union of Geodesy and Geophysics (IUGG) after recognizing that the Geodetic Reference System of 1967 adopted at the XIV General Assembly of IUGG, Lucerne, 1967, no longer represents the size, shape, and gravity field of the Earth to an accuracy adequate for many geodetic, geophysical, astronomical and hydrographic applications [9]. Thus gravity values computed based on the Geodetic Reference System of 1967 can be converted to the new Geodetic Reference System of 1980 by equation (3) below;

$\Upsilon 1980-\Upsilon 1967=(0.8316+0.0782 \sin 2 \varphi-0.0007 \sin 4 \varphi)$ mgal

where; $\varphi$ is the latitude in radians.

\subsubsection{Removal of the Honkasalo Term.}

IGSN-71 values include a correction of the Honkasalo term [12] which removes the average part of the tidal force. This correction term has been deemed inappropriate [13] because of resulting errors in calculation of the geoid from gravity values corrected with the Honkasalo term. Therefore, the Honkasalo term, $\Delta \mathrm{g}_{\mathrm{h}}$, was 
removed from all the measured gravity values that had been referenced to the IGSN-71 station by adding a latitudinal varying correction in milligals, given by the equation (4) below;

$\Delta \mathrm{g}_{\mathrm{h}}=0.0371\left(1-3 \sin ^{2} \varphi\right)$

where $\varphi$ is the latitude south or north of the gravity station and it is in radians.

The two corrections were performed to the gravity values at each reference station. Finally, after ensuring that dial readings were clean from drift and that gravity values of the reference stations are updated, the difference in gravity $(\delta g)$ between the new station and the IGSN station was calculated based on the equation (5) below where $\mathrm{K}$ is the calibration constant and $\delta \mathrm{s}$ is the difference in scale value in the two stations.

$\delta g=K * \delta s$

This value $(\delta g)$ was added to the reference values to obtain the possible value of the new station. Since three reference values were used, three possible values of the new station were obtained and these values were slightly different due to errors associated with them. To obtain the most probable absolute gravity value of the new station, least squares adjustment by weighted average was performed to the three values and statistical analysis was done to assess the quality of adjustment.

\subsection{Least Squares Adjustment by Weighted Average}

In mathematical terms, a least squares adjustment defines best fit solution for weighted measurements by finding a minimum for the sum of the squares of the measurement residual. A measurement residual is the amount needed to correct a measurement for it to fit into the best fit solution found by the least-squares adjustment. Various parameters necessary to perform the adjustment are defined below;

\subsubsection{Calibration Constant}

Calibration constant given for the gravimeter by the manufacturer is $0.1004 \mathrm{mgal} / \mathrm{div}$, but this value is subject to change due to aging, usage, and vibrations due to transportation of the equipment. A new calibration constant of $0.7543 \mathrm{mgal} / \mathrm{div}$ with of standard deviation of $0.05604 \mathrm{mgal} / \mathrm{div}$, was obtained by finding a weighted average of twenty calibration constants (two from each county). The two calibration constants from each county were obtained by equating absolute gravity difference of two reference stations with the difference in their gravimeter dial readings as shown in equation (5) and equation (6).

$$
\begin{aligned}
& K=\frac{\left(G^{2 n d}-G^{1 s t}\right)}{\left(D^{2 n d}-D^{1 s t}\right)} \\
& K=\frac{\left(G^{3 r d}-G^{1 s t}\right)}{\left(D^{3 r d}-D^{1 s t}\right)}
\end{aligned}
$$

Where $\mathrm{G}^{1 \mathrm{st}}, \mathrm{G}^{2 \mathrm{nd}}, \mathrm{G}^{3 \mathrm{rd}}$ and $\mathrm{D}^{1 \mathrm{st}}, \mathrm{D}^{2 \mathrm{nd}}, \mathrm{D}^{3 \mathrm{rd}}$ are the absolute gravity values and gravimeter dial readings of the $1^{\text {st }}, 2^{\text {nd }}$, and $3^{\text {rd }}$ reference stations respectively. $\mathrm{K}$ is the calibration constant of the equipment.

\subsubsection{Error Propagation}

For every measurement there has to be errors. Some of the errors can be removed by just looking at the field data while others can't be removed. Thus when these measurements are used in mathematical calculations, the errors associated with the measurements tend to propagate to the final result. In order to take into consideration these errors, the general formula in equation (7) was the main guiding principle in every mathematical calculation. Where $\mathrm{A}(\mathrm{x}, \mathrm{y})$ is a function with a variables $\mathrm{x}$ and $\mathrm{y} . \partial \mathrm{A}(\mathrm{x}, \mathrm{y}), \partial \mathrm{x}$, and $\partial \mathrm{y}$ are the errors in $\mathrm{A}(\mathrm{x}, \mathrm{y}), \mathrm{x}$, and y respectively.

$$
\partial A(x, y)=\sqrt{\left(\frac{d A}{d x} \partial x\right)^{2}+\left(\frac{d A}{d y} \partial y\right)^{2}}
$$

\subsubsection{Statistics}

Statistics are used in surveying to analyze repeated measurements and draw conclusions about the quality of the said measurements and are based on the laws of probability [14]. The various statistical terms and equations that have been used here are described as follows;-

Residue (v). The difference between adjusted value and the measured value or the amount the measurement has adjusted. It will be denoted by v. Having approximately $50 \%$ of the residue as negative and approximately $50 \%$ as positive is an indication of normally distributed data set. 
Residue $=$ adjusted value (e.g. Mean height $)-$ measured value $($ e.g. height $)$

Variance $\left(S^{2}\right)$ and Standard deviation $(S)$. Variance is a measure of precision of data set and will be denoted by $S^{2}$ while standard deviation is used to draw conclusion about probability. Approximately $68 \%$ of data will fall within the range defined by the standard deviation. Standard deviation is the square root of variance and will be denoted by $\mathrm{S}$.

$\mathrm{S}=\sqrt{S^{2}}=\sqrt{\frac{\sum v^{2}}{n-1}}$

Where $\mathrm{n}$ is the number of data sets.

Weights $(w)$. This are estimates of the relative reliabilities of observations. A high precision as indicated by a small standard deviation implies a good observation and hence high weight. Conversely, a low precision as indicated by a large standard deviation implies poor observation and hence a small weight. Weights are generally based on the reciprocal of standard deviation as shown by equation (9). Weights will be denoted here by $w$.

$w=\frac{1}{S^{2}}$

Weighted Mean $(X w)$. This is a mean where some values contribute more to the final value as compared to others due to the weight assigned to them. It will be denoted as $X w$.

$X w=\frac{\sum X i W i}{\sum W i}$

Where; $X w=$ weighted mean, $W i=$ Weight assigned to measurement $X i$.

Standard Deviation of the Weighted Mean $\left(S_{X w}\right)$

$S_{X w}=\sqrt{\frac{\sum w v^{2}}{\left(\sum w\right)(n-1)}}$

Where; $w=$ Weight assigned to the measurement $X, v=$ residual, $n=$ number of measurements.

Normalized Residuals $\left(N_{R}\right)$. This is the ratio of residuals to the standard deviation or error estimate. It will be denoted as $\mathrm{N}_{\mathrm{R}}$. For a normally distributed data set, $68 \%$ of normalized residuals should be equal to or less than one. Normalized residuals equal to or greater than three should be closely examined as potential outliers. Normalized residuals are used to indicate the weighting of individual measurement.

$\mathrm{N}_{\mathrm{R}}=\frac{|v|}{S}$

Degrees of freedom $(D F)$. This is the number of measurements in excess of those needed to solve for the unknowns. It will be denoted as DF.

$\mathrm{DF}=($ Total number of measurements + Total number of fixed values - Total number of Measurements to be determined.

Standard Error of Unit Weight. This is used to assess the weighting that has been applied to the entire network. If the weighting was perfect the standard error of unit weight would be equal to one.

Standard Error of Unit weight $=\sqrt{\frac{\sum w v^{2}}{D F}}$

Chi-square test. This is used to evaluate the standard error of unit weight. It answers the question, do the residuals $(v)$ reflect error estimations based on the resultant standard error of unit weight? In order to pass the standard error of unit weight must fall within the Chi-square range. This range is predicated on degrees of freedom. The Chi-square test is normally performed at the $95 \%$ confidence level (for surveying data) in what is termed as two tailed test. The two tailed test means the standard error of unit weight can be too high or too low.

\section{Results And Discussion}

The main software that was used to do calculations was Microsoft excel. The results of the calculations and the absolute gravity values of the new stations are show in the tables below for Kajiado County. 
Table 2: Results of calculations for Kajiado County

\begin{tabular}{|c|c|c|c|c|c|}
\hline & \multicolumn{4}{|c|}{ KAJIADO COUNTY } \\
\hline & & $1^{\text {st }} \operatorname{Ref}$ & $2^{\text {nd }}$ Ref & $3^{\text {rd }} \operatorname{Ref}$ & New Station \\
\hline \multirow{2}{*}{$\begin{array}{l}\text { Co- } \\
\text { ordinates }\end{array}$} & Easting & 254336 & 252627 & 252798 & 252289 \\
\hline & Northing & 9796593 & 9792598 & 9789445 & 9795389 \\
\hline \multicolumn{2}{|c|}{ Absolute Gravity Value (mgal) } & 977562.4 & 977585.3 & 977587.5 & \\
\hline \multicolumn{2}{|c|}{$\begin{array}{l}\text { Conversion from } 1967 \text { to } 1980 \\
\text { geodetic sytem (mgal) }\end{array}$} & 0.831680 & 0.831684 & 0.831686 & \\
\hline \multicolumn{2}{|c|}{ Honkasalo Term (mgal) } & 0.036987 & 0.036981 & 0.036977 & \\
\hline \multicolumn{2}{|c|}{ Updated Gravity Value (mgal) } & 977563.2687 & 977586.1687 & 977588.3687 & \\
\hline \multicolumn{2}{|c|}{ Weighted Dial Reading } & $\begin{array}{l}495.654 \\
\pm 1.174 \\
\end{array}$ & $\begin{array}{l}528.295 \\
\pm 0.627 \\
\end{array}$ & $\begin{array}{l}535.767 \\
\pm 1.89 \\
\end{array}$ & $\begin{array}{l}496.387 \\
\pm 1.554 \\
\end{array}$ \\
\hline \multicolumn{2}{|c|}{$\Delta \mathrm{s}$ (New Station -Ref Station) } & $\begin{array}{l}0.733 \\
\pm 1.948\end{array}$ & $\begin{array}{l}-31.908 \\
\pm 1.675\end{array}$ & $\begin{array}{l}-39.380 \\
\pm 2.445\end{array}$ & \\
\hline \multicolumn{2}{|c|}{ Calibration Constant } & \multicolumn{4}{|c|}{$0.75423 \pm 0.05604$} \\
\hline \multicolumn{2}{|c|}{$\Delta \mathrm{g}$} & $\begin{array}{l}0.5528 \\
\pm 1.4695\end{array}$ & $\begin{array}{l}-24.0661 \\
\pm 2.1897\end{array}$ & $\begin{array}{l}-29.7017 \\
\pm 2.8768\end{array}$ & \\
\hline \multicolumn{2}{|c|}{$\begin{array}{l}\text { Possible Absolute Gravity Value Of } \\
\text { New Station }\end{array}$} & $\begin{array}{l}977563.8215 \\
\pm 1.4696\end{array}$ & $\begin{array}{l}977562.1026 \\
\pm 2.1897\end{array}$ & $\begin{array}{l}977558.667 \\
\pm 2.8768\end{array}$ & \\
\hline \multicolumn{2}{|c|}{ Absolute Gravity Of New Station } & \multicolumn{4}{|c|}{977562.5831} \\
\hline \multicolumn{2}{|c|}{ Standard Deviation } & \multicolumn{4}{|c|}{1.2836} \\
\hline \multicolumn{2}{|c|}{ Residues } & -1.238 & 0.481 & 3.916 & \\
\hline \multicolumn{2}{|c|}{ Normalized Residues } & 0.8426 & 0.2195 & 1.3613 & \\
\hline \multicolumn{2}{|c|}{ Standard Error Of Unit Weight } & \multicolumn{4}{|c|}{1.1427} \\
\hline
\end{tabular}

Absolute gravity values of the new stations were obtained with minimal standard deviations. Residues at all stations obeyed the approximately $50 \%$ negative values and approximately $50 \%$ positive values rule, and also normalized residues were below 3.0 at all stations indicating that the adjustment process was excellent. Standard error of unit weight at all stations fall within the chi-square range at $95 \%$ confidence level with two degrees of freedom thus confirming that the adjustment process was excellent.

The gravity values obtained for the other stations are shown in the summarized tables below.

Table 3: Absolute gravity values of the new gravity stations

\begin{tabular}{|l|l|l|l|l|l|}
\hline Station & Kisii County & $\begin{array}{l}\text { Narok } \\
\text { County }\end{array}$ & $\begin{array}{l}\text { Bomet } \\
\text { County }\end{array}$ & $\begin{array}{l}\text { Kericho } \\
\text { County }\end{array}$ & $\begin{array}{l}\text { Nakuru } \\
\text { County }\end{array}$ \\
\hline Absolute Gravity (mgal) & $\mathbf{9 7 7 5 4 1 . 2 3 4 0}$ & $\mathbf{9 7 7 4 6 1 . 6 9 3 0}$ & $\mathbf{9 7 7 5 0 5 . 5 3 7 3}$ & $\mathbf{9 7 7 4 1 1 . 6 9 1 8}$ & $\mathbf{9 7 7 4 7 6 . 5 6 3 6}$ \\
\hline
\end{tabular}

Table 4: Absolute gravity values of the new gravity stations

\begin{tabular}{|l|l|l|l|l|}
\hline Station & Baringo County & $\begin{array}{l}\text { El-Geiyo } \\
\text { County }\end{array}$ & $\begin{array}{l}\text { Uasin-Gishu } \\
\text { County }\end{array}$ & $\begin{array}{l}\text { Trans-Nzoia } \\
\text { County }\end{array}$ \\
\hline Absolute Gravity (mgal) & $\mathbf{9 7 7 4 0 7 . 3 4 5 1}$ & $\mathbf{9 7 7 4 1 1 . 3 6 9 4}$ & $\mathbf{9 7 7 4 8 1 . 5 1 5 5}$ & $\mathbf{9 7 7 4 6 1 . 7 0 4 2}$ \\
\hline
\end{tabular}

Detailed information and sketch of the location of the new stations can be found in the catalogue of Kenya International Gravity Stations Network (KIGSN). Monumentation of the new station was done by cementing a brass disc on the ground. Each brass disc has a code on top (e.g KIGSN 001) to provide extra identification of the new station. Further survey is required to set up new gravity stations in the whole country.

\section{Acknowledgment}

I acknowledge my supervisors; Dr. John Githiri and Dr. Maurice K'orowe for their guidance during the entire research work. Many thanks to Jomo Kenyatta University of Agriculture and Technology for providing funding for the project, not forgetting Mr. Evance Odero and Mr. Elly Bogi, for their assistance during data collection.

\section{References}

[1] R. E. Moose, "The National Geodetic Survey Gravity Network," NOAA Technical Report NOS 121 NGS 39 , pp32, 1986.

[2] J. A. Duerksen, Pendulum gravity data in the United States (Washington: US Govt. print. Off., 1949)

[3] C. Morelli, Modern standards for gravity surveys, Geophysical Journal of the Royal Astronomical Society, 45(1), 1976, $199-199$.

[4] G. P. Woollard, and J. C. Rose, International gravity measurements (Tulsa: Society of Exploration Geophysicists, 1963)

[5] C. J. Swain, and M. A. Khan, Gravity measurements in Kenya, Geophysical Journal of the Royal Astronomical Society, 53(2), $1978,427-429$.

[6] R. C. Searle, and B. W. Darracott, A catalogue of gravity data from Kenya, to January 1971(Dept. of Geophysics and Planetary Physics, School of Physics: University of Newcastle upon Tyne, 1971)

[7] M. A. Khan, J. Mansfield, and C. J. Swain, Gravity Measurements in Kenya (London: University of Leicester, 1973)

[8] C. Morelli, C. Gantar, R. K. McConnell, B. Szabo, and U. Uotila, The international gravity standardization net 1971 (IGSN 71) (Italy: OSSERVATORIO GEOFISICO SPERIMENTALE TRIESTE, 1972) 
[9] H. Moritz, Geodetic reference system 1980, Journal of Geodesy, 54(3), 1980, 395-405.

[10] G. Boedecker, On the design of the International Absolute Gravity Basestation Network (IAGBN), Bulletin d'information-Bureau gravimétrique international, (57), 1985, 113-131.

[11] W. Torge, Gravimetry and tectonics: Publications of the Finnish Geodetic Institute (Geodesy and Geophysics), 115, 1993, 131-172.

[12] T. Honkasalo, On the tidal gravity correction, Bollettino di Geofisica Teorica ed Applicata, VI/21, 1964.

[13] M. Heikkinen, On the Honkasalo term in tidal corrections to gravimetric observations, Journal of Geodesy, 53(3), 1979, 239-245.

[14] R. M. Groves, F. J. Fowler Jr, M. P. Couper, J. M. Lepkowski, E. Singer, and R.Tourangeau. Survey Methodology (Vol. 561) (New Jersey: John Wiley \& Sons., 2009) 